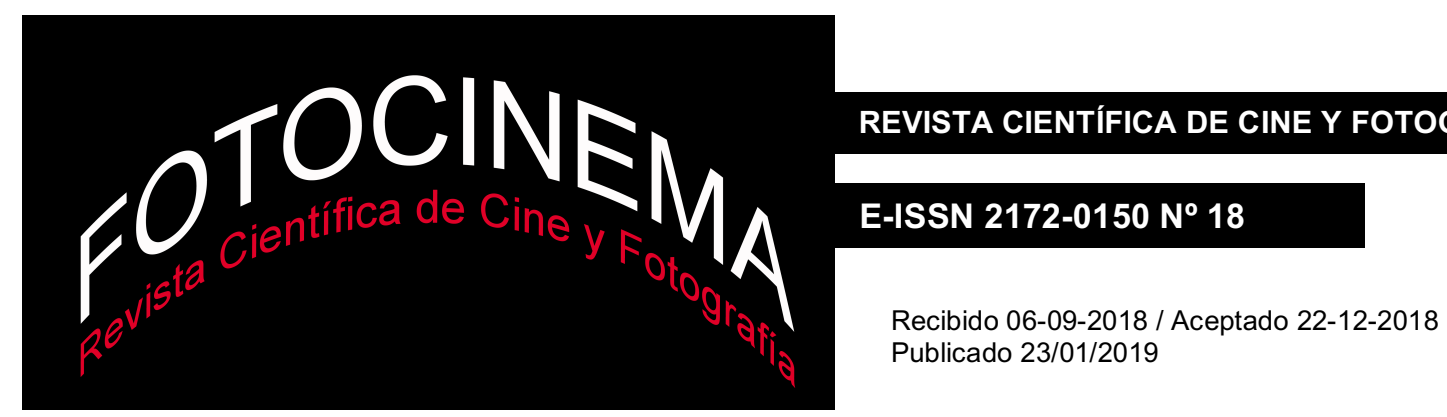

\title{
Los títulos de crédito como patrimonio fílmico. De documento informativo a obra plástica
}

\section{Title sequences as film heritage. From informative documents to artwork}

\author{
María Begoña Sánchez Galán \\ Universidad de Valladolid, España \\ mariabegona.sanchez@uva.es
}

\section{Resumen:}

Durante las primeras décadas del cine, antes de que se inventasen los sistemas de generación electrónica de caracteres, los títulos de crédito se dibujaban en papel, se filmaban y se editaban manualmente en las películas. Alguno de los miembros anónimos del equipo técnico, normalmente con habilidad para el diseño, se encargaba de dibujar los letreros, los símbolos textuales y gráficos, con los que comenzaba el relato fílmico. La mayoría de aquellos papeles se ha perdido, pero aún se conservan ejemplos que nos permiten estudiar cómo se elaboraban los títulos de crédito antes de la irrupción en la industria cinematográfica de los sistemas electrónicos y digitales. Este artículo analiza el papel físico, funcional y simbólico de dichos documentos a partir del estudio de una colección de rótulos y títulos de crédito que se conserva en la Colección-Museo de Filmoteca española y que han sido catalogados por la autora de este texto. Entre dichos papeles se encuentran títulos de crédito elaborados por Ramón de Baños y Manuel Hernández Sanjuán, dos importantes cineastas de la historia del cine español.

\begin{abstract}
:
During the first decades of Cinema History, before the electronic character generators were invented, title sequences were drawn in paper, filmed and manually edited in the movies. One of the many anonymous members of the technical team, usually skilled in the craft of design, was put in charge of drawing the signs, the textual and graphic symbols with whom the film story begun. The vast majority of those papers has been lost, but there are still examples that allow us to study how credit titles were made before the electronic and digital systems irrupted in the cinematographic industry. This article analyzes the physical, functional and symbolic role of these documents based on the study of a collection of signs and credit titles that are preserved in the Spanish Film Library and that have been catalogued by the author of this contribution. These papers include title sequences designed by Ramón de Baños and Manuel Hernández Sanjuán, two important filmmakers in the History of Spanish Cinema.
\end{abstract}

\section{Palabras clave:}

Títulos de crédito; créditos de apertura; indicios gráficos; arqueología del cine; Ramón de Baños; Manuel Hernández Sanjuán.

Keywords:

Title Sequences; Opening Credits; Graphic Signs; Film Archeology; Ramón de Baños; Manuel Hernández Sanjuán. 


\section{Introducción}

Los títulos de crédito son las palabras e imágenes que nos invitan a leer el relato audiovisual antes de que éste comience. Lo introducen, lo presentan, lo anuncian y, a veces, también lo ilustran. Son la portada del relato, la letra capitular del texto fílmico, la primera llamada de atención sobre una obra hecha de imágenes. Son dibujos y fuentes tipográficas, unas veces manuscritas y otras de imprenta, que contextualizan con signos textuales la historia que vamos a contemplar. A veces, incluso, estos signos tienen la capacidad de convertirse en un subrelato, en un tráiler que evoca las ideas y sensaciones que se nos van a mostrar en el espacio de tiempo que está enmarcado entre los títulos de inicio y los de fin.

Las palabras que se nos presentan en los títulos tienen la misión primordial de informarnos de la autoría y propiedad de la obra. Son el documento legal que reconoce la participación en la película de cada uno de los nombres propios que aparecen en la secuencia de créditos. Son, al mismo tiempo, los signos lingüísticos que nos obligan a "leer" el filme desde su inicio, antes incluso de empezar a interpretarlo (Stanizek, 2009). En palabras de Bordwell, son "narración transmitida como tipografía” (Bordwell, 1997, p.28), letras convertidas en imagen, figuras cargadas de un simbolismo que trasciende el significado textual de los caracteres.

En los primeros años del cinematógrafo, cuando las películas eran una curiosidad científica, no existían estos paratextos fílmicos. Los títulos de crédito nacieron como sello de propiedad en el momento en el que el cine empezó a extenderse como un espectáculo de masas y los productores vieron la necesidad de incluir en las películas un elemento que hiciese alusión a los derechos legales de la obra (Allison, 2011). Entrado ya el siglo XX, a medida que el cine se convertía en un contador de historias, los créditos evolucionaron para incluir el nombre de los primeros exponentes del star system y certificar el trabajo técnico de los pioneros (Bordwell, 1997).

Los títulos de crédito crecieron en extensión y en calidad estética a lo largo de los años veinte y treinta. Las letras blancas sobre fondo negro empezaron a fundirse con imágenes de presentación de la película y, a veces, se convirtieron en secuencias animadas (Braha y Byrne, 2013; Blancas, 2016). Al mismo tiempo, se 
crearon los primeros códigos de reconocimiento de las características principales de la obra a partir de sus títulos de crédito. La tipografía, el montaje y las imágenes que aparecían en la secuencia de créditos, trabajaban juntos para indicarle al espectador si estaba a punto de ver un western, una comedia, una película romántica, una de época o una de terror (Allison, 2006).

En los años 50, momento en el que el cine estadounidense empezó a competir con la televisión, los títulos vivieron una renovación creativa impulsada por la revolución de los formatos, los géneros, las tecnologías y la propia experiencia fílmica que estaba transformando el sector. Fue entonces cuando se permitió que los diseñadores gráficos volcasen toda su creatividad en el diseño de las secuencias de apertura de las películas. La figura más representativa de esta transición hacia nuevas formas expresivas fue Saul Bass, profesional multidisciplinar que llevaba desde la década de los treinta elaborando títulos de crédito y anuncios publicitarios para varias agencias y estudios de Hollywood. A partir de los años cincuenta, la renovación estética convirtió los créditos en una nueva forma de arte (Tylski, 2008, p. 41).

Durante todo este tiempo los rótulos con los que se realizaban los títulos de crédito se dibujaban manualmente en distintos soportes, de papel o acetato, que después se filmaban y se editaban en las películas. Por lo general se utilizaba una truca para elaborarlos y el encargo recaía en diseñadores gráficos, técnicos de efectos especiales y operadores de laboratorios cinematográficos. El desarrollo de sistemas electrónicos de generación de caracteres en los años 70, mejorados en la década de los 80 con la llegada de los ordenadores, terminó con la necesidad de realizar los dibujos sobre papel. Tal y como ha sucedido en todas las esferas del diseño, los trabajos pasaron a realizarse con equipos electrónicos y sólo excepcionalmente siguieron dibujándose manualmente sobre soportes tangibles. Aquellos rótulos dibujados a mano durante varias décadas, papeles frágiles y llenos de información, eran materiales profesionales que, una vez cumplida su función, dejaban de tener utilidad y se tiraban a la basura. Sólo en algunos casos quedaban archivados en los almacenes de las productoras o en los archivos de sus diseñadores, donde el fuego, el abandono y el tiempo hicieron que la mayor parte de ellos desapareciese. Miles de dibujos realizados a mano, de tipografías 
diseñadas para las películas, de fondos específicamente creados para una secuencia de créditos, desaparecieron para siempre. Pero no todos.

Afortunadamente, los museos del cine aún conservan ejemplos de aquellos soportes y es en esos materiales en los que queremos centrar este artículo. Concretamente, queremos presentar una colección que hemos estado identificando y catalogando a lo largo de los últimos años en la Colección-Museo de Filmoteca Española. Se trata de cientos de rótulos de distinta procedencia que, por la dificultad de su análisis y la carencia de recursos para abordar su estudio, han permanecido ocultos durante varias décadas. Su estado de conservación es óptimo por el buen tratamiento físico que han recibido, pero hasta ahora no habían sido correctamente organizados y por eso nunca antes se había difundido su existencia. La edición de este número de la revista Fotocinema, dedicada a los vínculos entre palabra e imagen, nos parece el lugar idóneo para presentarla.

Este artículo sintetiza una investigación de varios años cuyo objetivo principal ha sido el de identificar lo mejor posible los cientos de rótulos que forman parte de dicha colección. Esta identificación, que describiremos con mayor detalle en el apartado dedicado a la metodología, ha estado motivada por el deseo de dar respuesta a varias preguntas:

- ¿Cuántos documentos posee la colección? ¿De dónde vienen los rótulos? ¿Cuándo llegaron a la institución?

- ¿̇A qué época pertenecen? ¿Quién los realizó? ¿Para qué películas?

- ¿Cuál es la función de cada uno de los documentos? ¿Responden todos ellos a un mismo objetivo? ¿Se pueden establecer distintas funcionalidades para los rótulos y títulos de crédito de esta colección?

Los títulos de crédito que hoy presentamos son materiales físicos, documentos patrimoniales de la historia de nuestro cine, resultado directo de las actividades laborales y técnicas de la industria cinematográfica. Es por eso por lo que, para abordar su estudio, hemos recurrido a las prácticas de la arqueología industrial aplicadas al cine, metodología habitual de los procesos de recuperación de materiales que se lleva a cabo en las instituciones dedicadas a la conservación del patrimonio cinematográfico. El acercamiento a estos rótulos requiere, al mismo tiempo, de una mirada histórica que nos acerque a la época en la que fueron realizados. Abordaremos estos puntos en apartados posteriores, pero antes de 
ello nos gustaría hacer un repaso de las aportaciones teóricas que se han publicado en torno a los títulos de crédito.

\section{Estado de la cuestión}

Tal y como hemos comentado en líneas anteriores, este artículo observa los títulos de crédito desde el punto de vista de su materialidad física y para ello se apoya en las metodologías propias de la recuperación del patrimonio fílmico. Hasta el momento, desafortunadamente y como una de las dificultades que han ralentizado nuestra investigación, no hemos conseguido localizar estudios científicos previos que analicen los títulos de crédito desde esta perspectiva, y la causa más probable de esta carencia es la propia escasez de dichos materiales. La mayoría de los dibujos originales que se realizaron para rotular las películas se ha perdido y no se puede estudiar aquello que no existe.

Los libros y artículos que analizan el papel de los títulos de crédito en las películas se basan en la secuencia que aparece ya editada en el filme. Esta perspectiva de los títulos de crédito, su resultado final y el análisis de su contenido, sí que ha recibido atención por parte de los investigadores. En este apartado queremos recoger algunas aportaciones destacadas, entre las que encontramos las de Deborah Allison, investigadora que ha localizado numerosas fuentes bibliográficas y hemerográficas que comprenden desde la década de los veinte hasta finales del siglo XX. Sus publicaciones son una fuente de información fundamental para el estudio de la evolución histórica de los títulos de crédito (Allison, 2002, 2006, 2011 y 2015).

Igualmente interesantes resultan los múltiples textos que estudian la obra de Saul Bass y sus aportaciones al diseño de títulos de crédito. Los análisis de su obra son un completísimo repaso de la evolución del diseño gráfico y el marketing cinematográfico a lo largo del siglo XX. Podemos encontrar referencias a Saul Bass en casi todos los textos dedicados a los títulos de crédito, pero en este repaso nos permitimos la libertad de recomendar los libros de Bass y Kirkham (2011) y Horak (2014).

En España contamos con numerosas contribuciones sobre la materia, entre las que destacamos las de Solana y Boneu (2008, 2106), Blancas (2002, 2016), Rey 
(2013, 2016), Gamonal (2005) y Ramírez (2016). En el contexto del cine español, no podemos dejar de citar la obra de Pablo Núñez, sin duda el autor de títulos de crédito más premiado de nuestra industria fílmica. Sus trabajos han sido objeto de múltiples artículos de divulgación en revistas cinematográficas, pero también es posible encontrar estudios pormenorizados de la obra de este importante maestro de la animación en España (Llorens \& Uris, 2001; González-Monaj, 2016).

Otros investigadores que han dedicado atención a los títulos de crédito desde diversos puntos de vista, y a los que merece la pena leer, han sido Tylski (2008), Aran (2011), Klecker (2015) y Zons (2015).

Tal y como indicábamos al inicio de nuestro repaso bibliográfico, no hemos sido capaces de localizar ningún texto relevante relacionado específicamente con la recuperación material de títulos de crédito en archivos y centros de documentación, a pesar de que la Arqueología de los Medios recibe cada vez una mayor atención por parte de los investigadores (Parikka, 2012; Noordegraaf et alt., 2013). Con este artículo nos lanzamos, por lo tanto, a una especie de vacío en el que la carencia de anclajes teóricos nos hace estar expuestos a múltiples errores conceptuales y metodológicos. El miedo a equivocarnos es, en cualquier caso, menor que el deseo de difundir la existencia de estos documentos con la esperanza de despertar el interés de otros investigadores que puedan enriquecer y corregir nuestras palabras.

\section{Aspectos metodológicos. Sobre la recuperación de la colección de rótulos de Filmoteca Española}

Antes de que se inventasen los sistemas de generación electrónica de caracteres, las letras y dibujos de los títulos de crédito eran fruto del trabajo manual de los profesionales del cine. Los rótulos eran paratextos que se trazaban a mano sobre un papel, documentos tangibles que, una vez utilizados, se archivaban o destruían, depende del caso, junto al resto de los materiales generados en la producción de la obra.

Hace muchos años, en el transcurso de una investigación complementaria, Elena Cervera (responsable entonces de la Colección-Museo de Filmoteca Española), 
nos mostró una enorme colección de estos documentos, papeles teñidos de negro con letras blancas, tan interesantes como desordenados. Se trataba de cientos de folios, cartulinas y hasta de papel de empapelar las paredes, en los que se habían trazado letras y dibujos destinados a servir como títulos de crédito, insertos y sobreimpresiones de tráileres y anuncios. En ellos se leían títulos de películas, nombres de actores, de técnicos, de productores, de realizadores, frases publicitarias, logotipos de productoras, textos de sala, rótulos de fin... Un número indefinido de papeles mezclados sin un orden específico, de los que no se conocía una procedencia exacta y que no podían ser atribuidos a ninguna obra concreta. En total, dos docenas de sobres que contenían cientos de papeles sin identificar (F1).

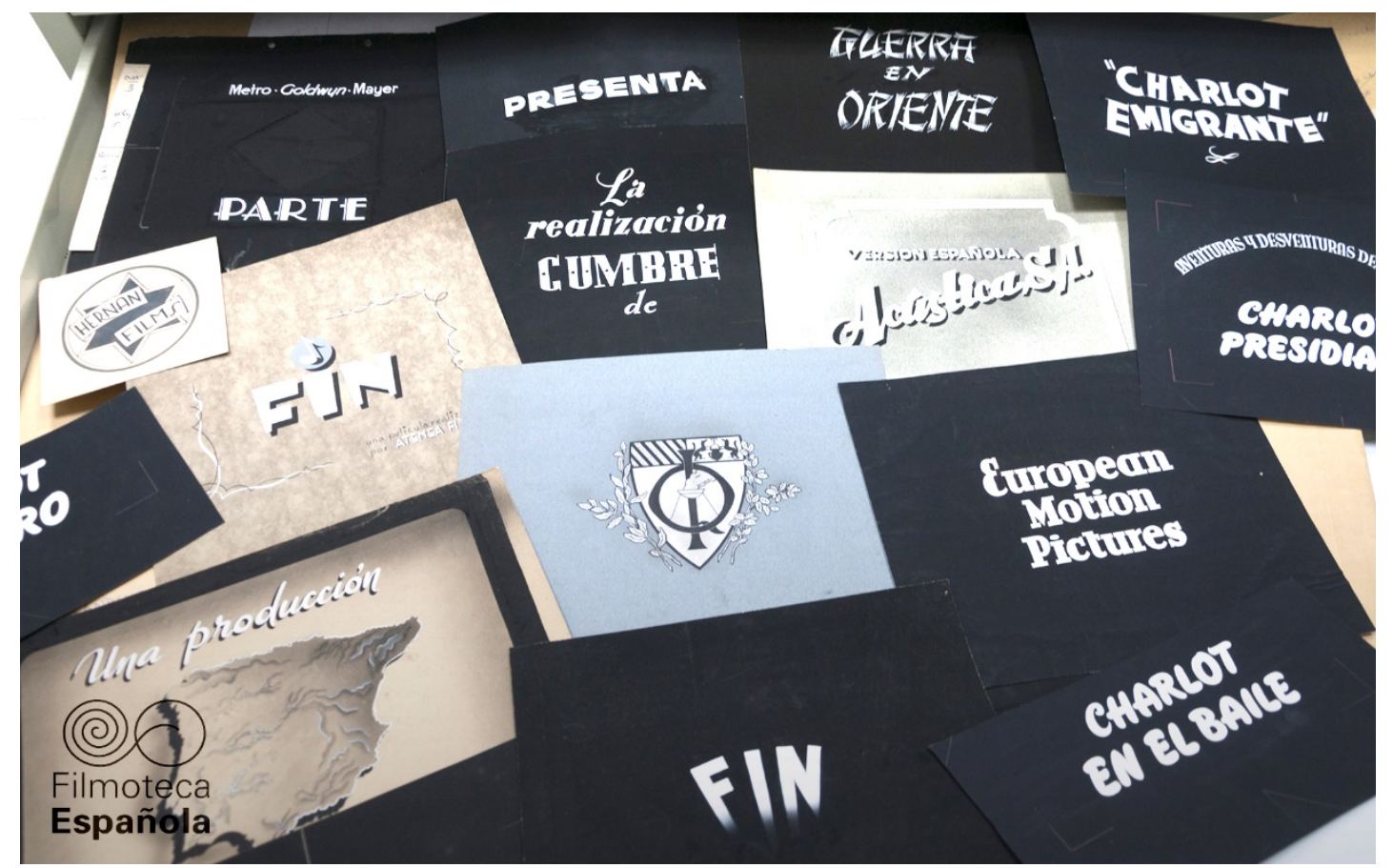

F1. Contenido de uno de los sobres de rótulos. Colección-Museo Filmoteca Española.

El lote invitaba a bucear en aquellas letras y a investigar todo lo que se pudiese sobre ellas, pero el desorden de los papeles era tal, que no éramos capaces de calcular el tiempo que íbamos a necesitar para poder sacar adelante aquel proyecto. A pesar de no poder dedicarle una atención absoluta, decidimos embarcarnos en esta aventura conscientes de que íbamos a tardar años en organizar aquellos documentos. Afortunadamente, contábamos con el respaldo y la ayuda de los trabajadores de Filmoteca, siempre dispuestos a apoyar 
desinteresadamente a los investigadores que mostramos interés en los materiales que allí se conservan ${ }^{1}$.

En el momento de comenzar nuestra investigación, y ante aquella colección de papeles, sólo teníamos clara una cosa: que el contexto original de los documentos (elemento básico en cualquier trabajo de recuperación de materiales), se había perdido y no íbamos a ser capaces de recuperarlo. Era necesario comenzar un proceso de identificación exhaustiva que nos permitiese agrupar con la mayor coherencia posible aquella cantidad indeterminada de papeles. La investigación en archivos fílmicos requiere del diseño de procedimientos específicos que permitan recuperar y analizar, de la mejor manera posible, los vestigios que nos han llegado del pasado. Cada proceso de investigación es diferente y, en este caso, diseñamos un procedimiento dividido en varias fases que vamos a resumir a continuación.

\subsection{Primera fase: clasificación provisional, datación e identificación de autores. Ramón de Baños y Manuel Hernández Sanjuán}

La colección llevaba décadas entre los fondos del museo y nadie recordaba con exactitud cuándo había llegado a la institución y en cuántos lotes. Elena Cervera (responsable de la Colección-Museo de Filmoteca Española) y Ramón Rubio (responsable del Departamento de Recuperación), tenían algunos indicios, pero no conseguimos localizar documentos que acreditasen la procedencia exacta y la fecha de entrada de aquellos papeles. Era necesario buscar el origen en los propios materiales.

Lo primero que hicimos para avanzar en esta tarea fue leer e interpretar las marcas que aparecían en el dorso de cada uno de los papeles. Muchos de ellos estaban numerados e incluían un sello con el nombre y la dirección de su autor, que resultó ser nada menos que Ramón de Baños, uno de los pioneros más importantes de nuestro cine. Gracias a dichas marcas pudimos agrupar varios

\footnotetext{
${ }^{1}$ No puedo dejar de agradecer y reconocer el inmenso apoyo que he recibido siempre de los trabajadores de Filmoteca Española, especialmente de Elena Cervera y Ramón Rubio, sin los que ninguna de mis investigaciones habría salido adelante. En esta ocasión conté, además, con la ayuda impagable de Elena Revilla López y Fátima Mercedes Marín Núñez, estudiantes del Grado de Historia del Arte de la Universidad Autónoma de Madrid, que me ayudaron a organizar los materiales en una de las fases finales del procedimiento. Su aportación fue fundamental porque, tras esta tarea, recogieron todos los datos e imágenes que habíamos generado e introdujeron la información en las bases de datos de la institución. Gracias a ellas ahora es posible consultar la ubicación, la descripción y el contenido de cada rótulo.
} 
cientos de papeles que estaban asociados, sin género de duda, al nombre del cineasta catalán. Ramón de Baños había comenzado su carrera dibujando los títulos e intertítulos de las películas de la Hispano-Films (Baños, 1991, p.29), tarea que compaginó posteriormente con la realización, filmación y edición de sus propias obras cinematográficas. Su biógrafo, Francesc de Lasa (1996), comenta que continuó realizando rótulos en los laboratorios en los que trabajó y, con posterioridad, en su propia productora. Estos datos acreditaban que los dibujos se habían realizado en su empresa.

No todos los papeles llevaban el sello de Ramón de Baños. Muchos de los documentos carecían de marcas al dorso y pertenecían a títulos que era difícil vincular con este autor, por lo que resultaba imprescindible seguir buscando pistas que ayudasen a organizar el fondo.

Una vez ordenado el primer grupo de papeles, pasamos a clasificar el resto a partir de sus detalles físicos. Uno a uno, observamos el gramaje, la textura del papel y la tipografía de cada trazo e inscripción. Esto nos permitió agrupar algunos documentos en función de sus características físicas y de las marcas halladas en el material. A continuación, pasamos a analizar su contenido. Papel a papel, fuimos tomando nota de los textos que aparecían escritos en ellos y los buscamos en libros, revistas y en las bases de datos cinematográficas, públicas y privadas, con las que trabaja Filmoteca Española. Algunos títulos fueron fáciles de identificar, pero otros contenían datos que aún no hemos sido capaz de localizar en ningún directorio.

En esta fase encontramos nuevos indicios que nos sirvieron para asociar un centenar de rótulos a la figura de Manuel Hernández Sanjuán, fotógrafo, pintor, cineasta y uno de los fundadores de la productora Hermic Films. Hernández Sanjuán se hizo construir una truca a mediados de los años 40 para utilizarla, según cuenta José López Clemente, en los documentales de arte que realizó en aquellos años (López, 1960, p.183). Entendemos que esa truca le sirvió también para filmar los títulos de crédito de las películas y documentales que realizó la productora y en los que participaron autores tales como el propio Manuel Hernández Sanjuán, Luis Torreblanca, José López Clemente, Eugenio Martín y Alfredo Castellón, cuyos nombres aparecen en los títulos de crédito que hemos recuperado. 
Esta primera y ardua organización provisional dio como resultado un listado de 1028 papeles y recortes que se agrupaban en torno a 184 títulos de películas. En este momento, identificadas sus características físicas y una vez agrupados en torno a su descripción, decidimos fotografiar uno a uno los documentos para tener un archivo digital que nos permitiese trabajar con flexibilidad, en base a su contenido y sin tener que acceder a los originales. Las fotografías resultaron imprescindibles en la fase siguiente de la investigación.

\subsection{Segunda fase: verificación de la presencia de los rótulos en los títulos de crédito de las películas}

Llegados a este punto, empezaba a ser imprescindible confirmar si nuestros rótulos se habían utilizado realmente, o no, en las secuencias de créditos de las películas y documentales con las que los estábamos relacionando. Si no aparecían en las obras fílmicas, debíamos replantearnos la función de aquellos papeles y la validez y utilidad del trabajo que estábamos realizando.

La tarea de localizar los casi dos centenares de títulos que habíamos anotado en fases anteriores tampoco fue fácil. Algunas de las películas se habían perdido, otras sólo podían consultarse en moviola y otras ni siquiera se llegaron a estrenar. Cuando la película estaba disponible en un formato de consulta, capturábamos las imágenes de los títulos de crédito y las comparábamos con las fotografías que habíamos realizado a los dibujos y rótulos de la colección. Si coincidían, quedaba demostrado que los documentos se habían elaborado para formar parte de una película. Esto nos permitía asignarle un título y una fecha de realización definitiva a los rótulos.
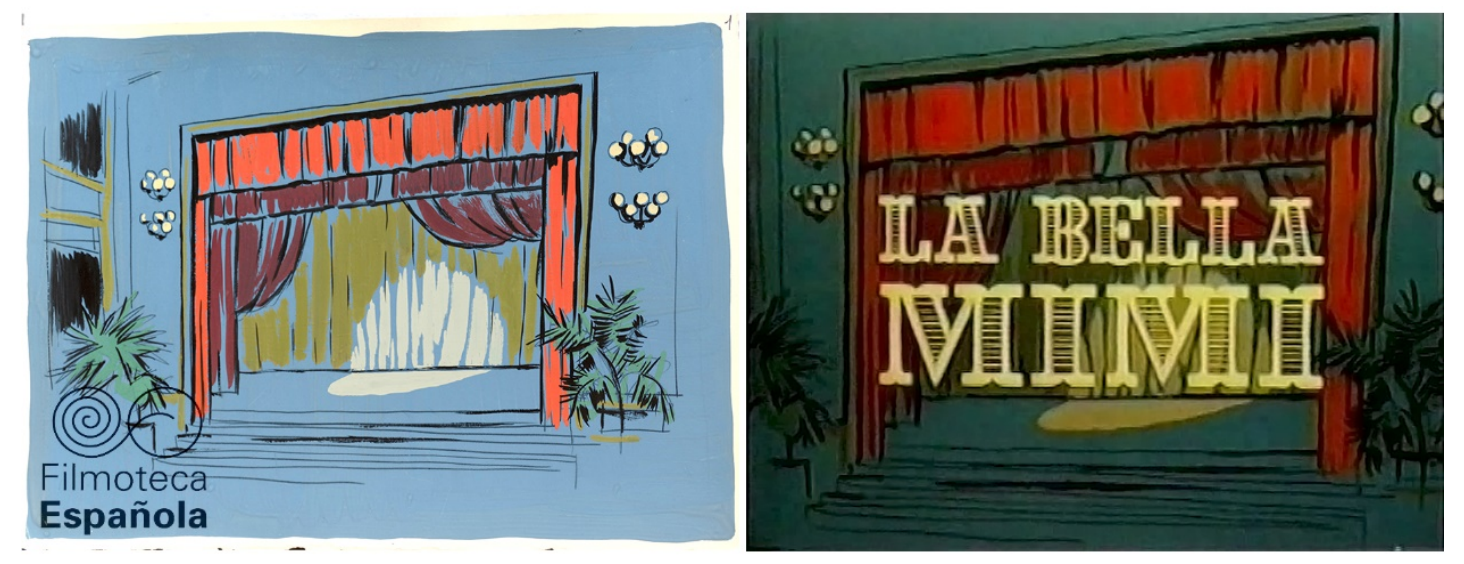

F2. Dibujo original (autor desconocido) y captura del título de la película La Bella Mimí (José María Elorrieta, 1961). Colección-Museo Filmoteca Española. 
Pongamos un ejemplo. En la figura $2(\mathrm{~F} 2)$ vemos el primer dibujo que aparece en la secuencia de créditos de La Bella Mimi (José María Elorrieta, 1961): a la izquierda mostramos la acuarela original que se conserva en nuestra colección y a la derecha la captura del título tal y como aparece en la película. Este dibujo fue fácil de identificar porque el dorso incluye unas indicaciones escritas a mano en las que se lee “dibujo no 1 para los letreros: Queta Claver y La Bella Mimí”. Verificada la cinta, comprobamos que la acuarela se utilizó como fondo de los dos primeros rótulos del filme. La secuencia completa incluye 21 rótulos inscritos sobre 10 fondos. No hemos localizado ninguno de los textos, pero conservamos las 10 acuarelas originales, pintadas sobre unas cartulinas que miden $25 \times 34 \mathrm{~cm} \mathrm{y}$ que, ahora, después de estas comprobaciones, están por fin convenientemente identificadas.

Cada verificación de un rótulo se convertía en un gran estímulo para esta investigación, porque confirmaba que el trabajo iba por buen camino y que estábamos recuperando piezas patrimoniales de la historia de nuestro cine.

\subsection{Tercera fase: reorganización de los documentos y gestión de datos}

Cuando consideramos que ya teníamos pruebas suficientes de la validez de nuestra primera clasificación, decidimos que había llegado el momento de reordenar todos los rótulos y de reagruparlos en torno a los títulos de las películas que les habíamos asignado. Tomar esta decisión fue difícil porque con esta reorganización rompíamos el orden en el que se habían conservado los materiales durante varias décadas. Teníamos, sin embargo, la convicción de que habíamos encontrado los documentos descontextualizados y reordenados de manera aleatoria, por lo que no estaba justificado dejarlos en su estado original. Por ejemplo, uno de los sobres contenía únicamente títulos de "fin" y mezclaba materiales con el sello de Ramón de Baños y con marcas de la truca de Hernández Sanjuán. Sabíamos que esos rótulos habían llegado de procedencias diferentes y en épocas distintas, lo que demostraba que, una vez en Filmoteca, alguien había distribuido los papeles en base a criterios que desconocíamos y había roto para siempre su contexto de entrada en el archivo. Decidimos, por lo tanto, que lo mejor era agruparlos por películas y, por si acaso, conservamos un listado con el orden en el que nosotros los habíamos encontrado. 
Una vez reagrupados los rótulos en torno a los títulos de las películas a las que pertenecían, las trabajadoras de la Colección-Museo de Filmoteca Española, ayudadas por dos estudiantes que en aquel momento estaban realizando sus prácticas en la institución, recogieron todos los datos y las imágenes que habíamos generado en las fases anteriores de la investigación e introdujeron toda la información en las bases de datos del museo.

Por fin, años después de haber empezado a buscar el marco general de este puzle, empezábamos a ver figuras y datos concretos. Sabíamos que teníamos 1028 dibujos y rótulos, realizados en las décadas de los 40, 50 y 60, y filmados al menos en dos trucas, la de Ramón de Baños y la de Manuel Hernández San Juan. Una parte de ellos se dibujó para crear los títulos de crédito originales de varias películas españolas, otros para traducir a nuestro idioma los rótulos e insertos de películas extranjeras y el resto para crear sobreimpresiones incluidas en películas, tráileres y material publicitario.

\section{Resultados: lo que se extrae de nuestra colección de rótulos}

Los años que hemos estado inmersos en el proceso de observación de este millar de papeles nos han llevado a darle un valor extraordinario a cada pieza, pero también nos ha permitido observar una serie de características comunes que justifican la conservación y difusión de esta colección. La historia, evolución, factura, tipografía o autoridades que aparecen en ellos se estudian perfectamente desde la propia película, de manera que el valor de estos rótulos no está en su contenido, sino en su "materialidad", en la cualidad física que permite que podamos tocarlos y analizarlos como objetos tangibles y patrimoniales.

\subsection{Papeles que son piezas de museo}

Cada uno de estos papeles es una obra, cada documento es una pieza de museo. La mayoría de los rótulos que hemos recuperado muestran letras blancas sobre un fondo negro, pero también se conservan algunos dibujos de gran belleza que destacan sobre el resto de los papeles de la colección. Todos ellos, sin excepción, y al margen de su calidad estética, son restos arqueológicos industriales que ayudan a profundizar en la historia de nuestro cine y de nuestras películas. Son, 
en términos académicos, "patrimonio de la sociedad industrial" y, como tal, merecen ser valorados, protegidos y conservados (Cerdá, 2008, p.228).

La afirmación de que estos papeles son piezas de museo no es nueva. Cuando las instituciones recuperan títulos de crédito, les dan los mejores cuidados posibles y los incluyen entre los materiales de estudio de la industria cinematográfica. Los museos del cine y los coleccionistas no son ajenos a la importancia de estos documentos y, gracias a ellos, es posible acceder a algunos ejemplos con relativa facilidad. La plasticidad de los dibujos que se realizaron para algunos títulos de crédito es tal, que han llegado a formar parte de grandes exposiciones. Recordamos, por ejemplo, las secuencias de apertura de Saul Bass que se incluyeron en la muestra Hitchcock, más allá del suspense (organizada por la Fundación Telefónica en el año 2016), o los títulos de crédito originales, en soporte papel, de la película Sueños que el dinero puede comprar (Dreams than Money can Buy, Hans Richter, 1946), expuestos en Arte y Cine. 120 años de intercambio (organizada en el año 2017 por la Obra Social "La Caixa”).

Estos dibujos y letras son, por lo tanto, elementos patrimoniales de nuestra industria audiovisual, con un contenido creativo que en ocasiones los convierte en obra plástica y que, siempre, ayudan a estudiar la historia de nuestro cine. Ejemplo de los títulos de crédito originales de películas españolas que se conservan en esta colección son: Escuadrilla (Antonio Román, 1941), Una chica de opereta (Ramón Quadreny, 1943), Brindis a Manolete (Florián Rey, 1948), Tempestad en el alma (Juan de Orduña, 1949), Niebla y sol (José María Forqué, 1951), Hay un camino a la derecha (Francisco Rovira Beleta, 1953) y Sol andaluz (Domenec Bou, 1954), entre otros.

En lo que se refiere a documentales, citamos como ejemplo los títulos recuperados de: Fiesta del fuego (Luis Torreblanca, 195), Momento de Velázquez (Eugenio Martín, 1956), Costas del Sur (Manuel Hernández Sanjuán, Ernesto Halffter, 1956), Romance de una batalla (Eugenio Martín, 1956), Carlos V defensor de Occidente (Luis Torreblanca, 1959), Bailes de Galicia y Sonata Gallega (Alfredo Castellón, 1960) e Idilio en Ibiza (José López Clemente, 1961). 

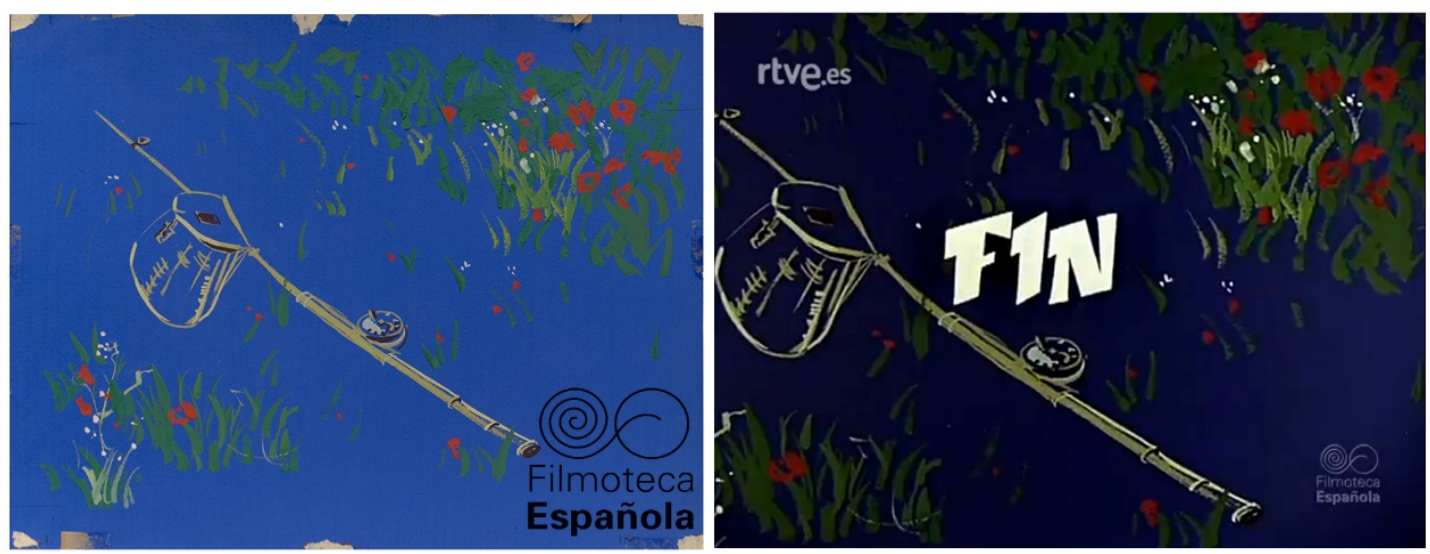

F3. Dibujo original (autor desconocido) y captura del fotograma final del documental Truchas y Salmones (Luis Torreblanca, 1957). Colección-Museo Filmoteca Española.

\subsection{Rótulos que ayudan a estudiar la técnica cinematográfica}

Los papeles que hemos recuperado ayudan a estudiar cómo se realizaban los títulos de crédito antes de la invención de los equipos de generación electrónica de caracteres. Básicamente, observamos dos técnicas diferentes en la elaboración de la secuencia de créditos de nuestra colección: la filmación de los rótulos, letras blancas sobre fondo negro y su edición directa en la cabecera del filme o la sobreimpresión de esas letras blancas en imágenes rodadas como fondo de los títulos.

La sobreimpresión de rótulos se utilizaba, asimismo, en otros momentos de la cinta y se consideraban parte de los "efectos especiales" de la película. Un ejemplo de ello son los letreros que aparecían en una de las secuencias de Niebla y sol (José María Forqué, 1951). El técnico de efectos especiales de esta película fue Ramón de Baños, al que le hemos atribuido la autoría, tanto de estas sobreimpresiones (F4), como de la secuencia inicial de créditos de la película (F6). Ambos ejemplos se conservan en la colección de rótulos que hemos recuperado.

Este tipo de materiales ilustran, por lo tanto, la evolución de las técnicas del montaje y son un ejemplo de las herramientas y métodos empleados en la elaboración de las películas a lo largo de la historia del cine. 

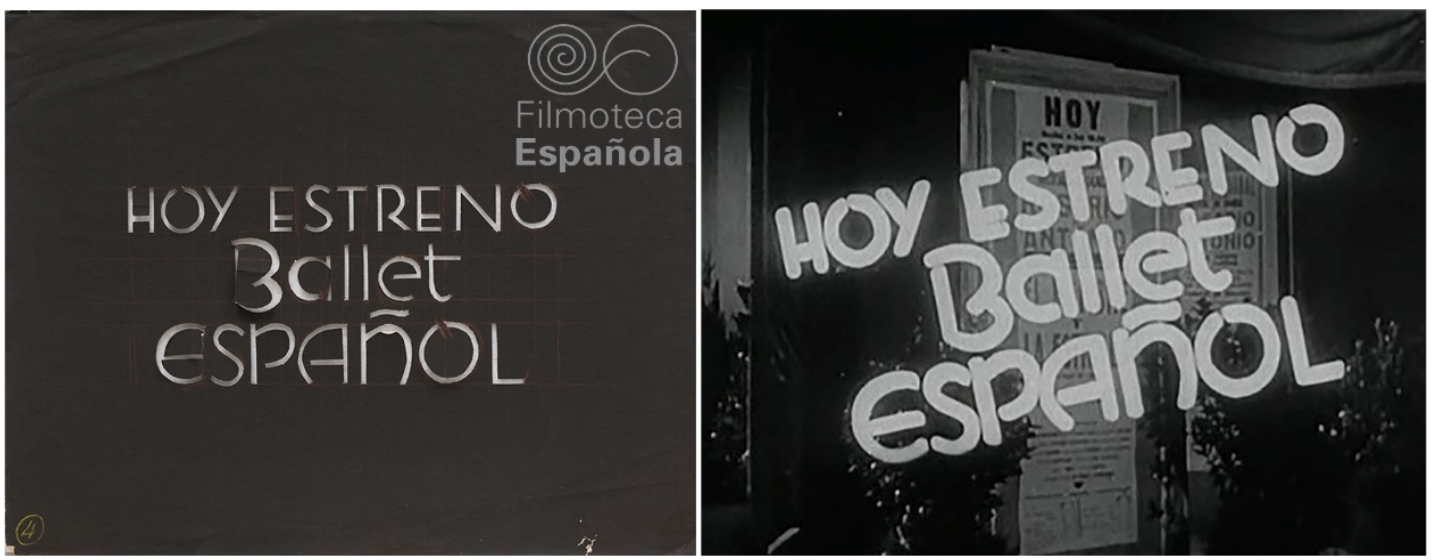

F4. Rótulo realizado por Ramón de Baños y captura de su sobreimpresión en un plano de la película Niebla y sol (José María Forqué, 1951). Colección-Museo Filmoteca Española.

\subsection{Rótulos que descubren películas perdidas}

A lo largo del proceso de identificación de los rótulos nos encontramos con dibujos que ofrecían títulos de obras que no conseguimos localizar en ninguna base de datos de películas, cortometrajes o documentales. Los expertos de Filmoteca Española, entre ellos Ramón Rubio, cotejaron sin éxito nuestra lista de títulos con directorios y catálogos especializados, alguno de ellos inéditos y elaborados por el propio Ramón a lo largo de muchos años de trabajo.

En el mejor de los casos, tuvimos la suerte de localizar alguno de esos títulos en el Archivo General de la Administración de Alcalá de Henares (AGA), lo que demostraba que las películas se habían presentado a censura, pero no permitía averiguar si se habían filmado o no. La tónica habitual es que los títulos de crédito se realicen en la fase de postproducción (Gamonal, 2005, p. 6), pero no existe una fórmula fija para su elaboración, por lo que no sabemos si nuestros rótulos se dibujaron después de que la obra estuviese terminada, aunque ésta nunca llegase a los cines, o si se realizaron con antelación al rodaje y las películas nunca se llegaron a filmar. Tendremos que seguir investigando.

Un ejemplo de este tipo de obra son los dibujos que mostramos en la figura 5 ( $\mathrm{F}_{5}$ ), en la que podemos ver el título de un trabajo del que no se conserva copia alguna. La película se titula Travesuras de Don Febo y como realizadores de la cinta aparecen José M. Carnicero, Edit Frank y Ramón de Baños. Por los datos que aparecen en el AGA, es probable que se trate de una película publicitaria realizada en el año 1948. 

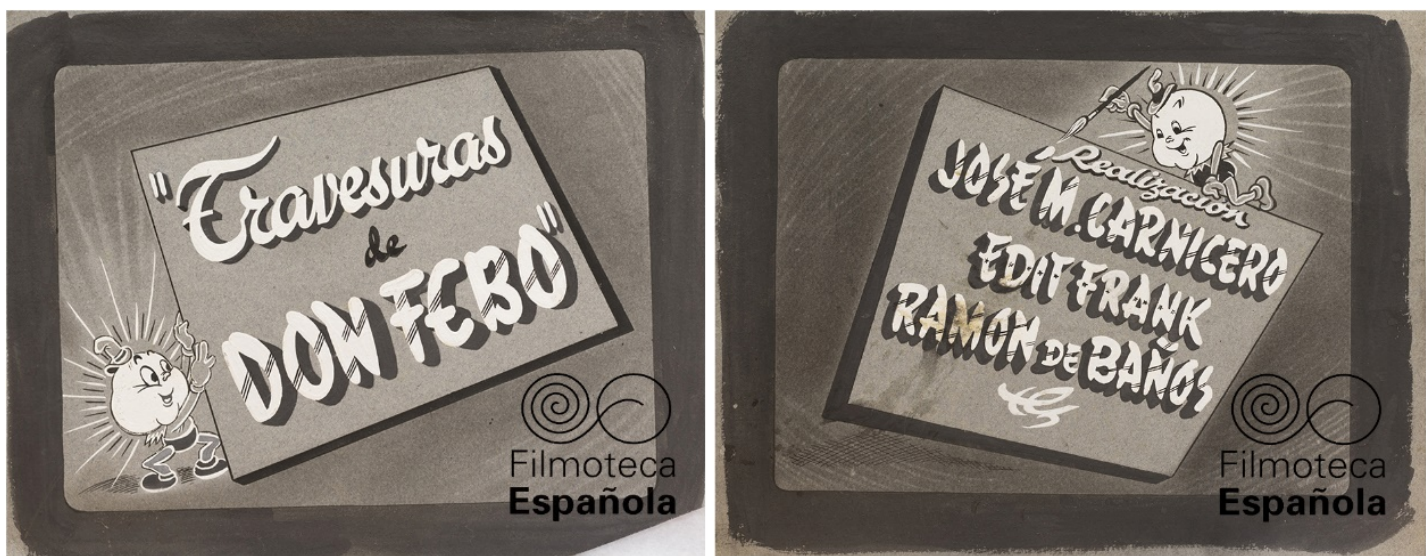

F5. Dibujos de Ramón de Baños para la película Travesuras de don Febo (José M Carnicero, Edit Frank y Ramón de Baños, c.1948). Colección-Museo Filmoteca Española.

Hemos contrastado algunos de estos títulos con su expediente de censura para intentar averiguar datos sobre sus autores y su contenido. Creemos que en esta búsqueda se podrían localizar obras desconocidas de autores destacados, pero todavía queda muchísimo trabajo por hacer para averiguar si estas letras y dibujos van a permitir sumar nuevos títulos a la historia del cine español.

Otra línea similar que tenemos que investigar es si en nuestro fondo se conservan rótulos de películas que sí se llegaron a filmar, que están citadas en la filmografía de directores de reconocido prestigio y de las que no se ha conservado ninguna copia. Tenemos rótulos que pueden haber pertenecido a películas perdidas y así nos lo han confirmado los especialistas con los que lo hemos consultado. El hecho de no poder verificar si realmente se utilizaron en dichas obras, nos impide citar los títulos y autores que estamos investigando.

\subsection{Los dibujantes de rótulos son pioneros del diseño gráfico cinematográfico en nuestro país}

Si los grandes dibujantes de títulos de crédito fueron pioneros del diseño gráfico en los países en los que trabajaron (Bass \& Kirkham, 2001), los autores de los documentos que nosotros estamos estudiando pueden ser considerados, sin lugar a dudas, pioneros del diseño gráfico cinematográfico en España.

Ramón de Baños, autor de la mayor parte de los dibujos que hemos recuperado es, sin lugar a dudas, pionero del diseño gráfico aplicado al cine en nuestro país. También lo es Manuel Hernández Sanjuán, a quien hemos atribuido la edición de otra importante parte de la colección. 
Durante las cinco primeras décadas de la historia del cine, el dibujo de rótulos era un trabajo anónimo que recaía en cualquier técnico que tuviese facilidad para el dibujo. Sabemos que algunos realizadores trabajaron en este sector porque ellos mismos lo han contado en sus biografías, pero la lista de quienes han afirmado realizar estas tareas es muy corta. Probablemente el más conocido de ellos es Alfred Hitchcock, que en su entrevista con Truffaut comentó que su primer trabajo en el cine fue la elaboración de dibujos para títulos e intertítulos (Truffaut, 2010).

Ramón de Baños también dejó documentado su trabajo como dibujante de títulos en el libro en el que relataba sus primeros años de profesión. Él mismo contó que, cuando se incorporó a la Hispano-Films: “jo dibuixaba els títols de la portada i el subtítols, i els adornaba amb vinyetes molt artistiques” (Baños, 1991, p. 29).

De la lectura de anuarios, biografías e historias del cine español se deduce que gran parte de los títulos de crédito se elaboraba en los laboratorios cinematográficos. En el directorio que Juan Antonio Cabero incluyó en su historia del cine español, publicada en 1949, especificaba que entre 1941-1945 el laboratorio Madrid Films poseía “dos aparatos de reproducción de títulos y dibujos animados"; Palacio Films, además de tener un "laboratorio de revelado positivado", realizaba "títulos, cortinillas y dibujos animados"; el laboratorio de José María Bosch realizaba "títulos en todos los idiomas"; Cinefoto tenía una "sección de títulos con dos cámaras"; y Fontanals tenía "dos máquinas para títulos sonoros" y "una imprenta completa para la confección de títulos" (Cabero, 1949, pp. 552-553).

Ramón de Baños ayudó a montar algunos de estos laboratorios, entre otros el de José María Bosch, del que el historiador Francesc de Lasa dicen que eran: "les més antics de Barcelona en tiratge de còpies (...), tiratge de tìtols artístics amb moviment per a portades i trailers (...)” (De Lasa, 1996, p. 364).

También de la realización de títulos, en este caso para el Laboratorio Madrid Film, habló Eduardo García Maroto en su biografía al comentar que su jefe, Enrique Blanco, le confió "la confección de las letras versales de los títulos que se imprimieran" (García, 1955, p.25). Precisamente de la máquina para el tiraje de rótulos del Madrid Film es la fotografía que Rosa Cardona incluye en su artículo 
dedicado a la instalación de los primeros laboratorios cinematográficos españoles (Cardona, 1999, p. 65).
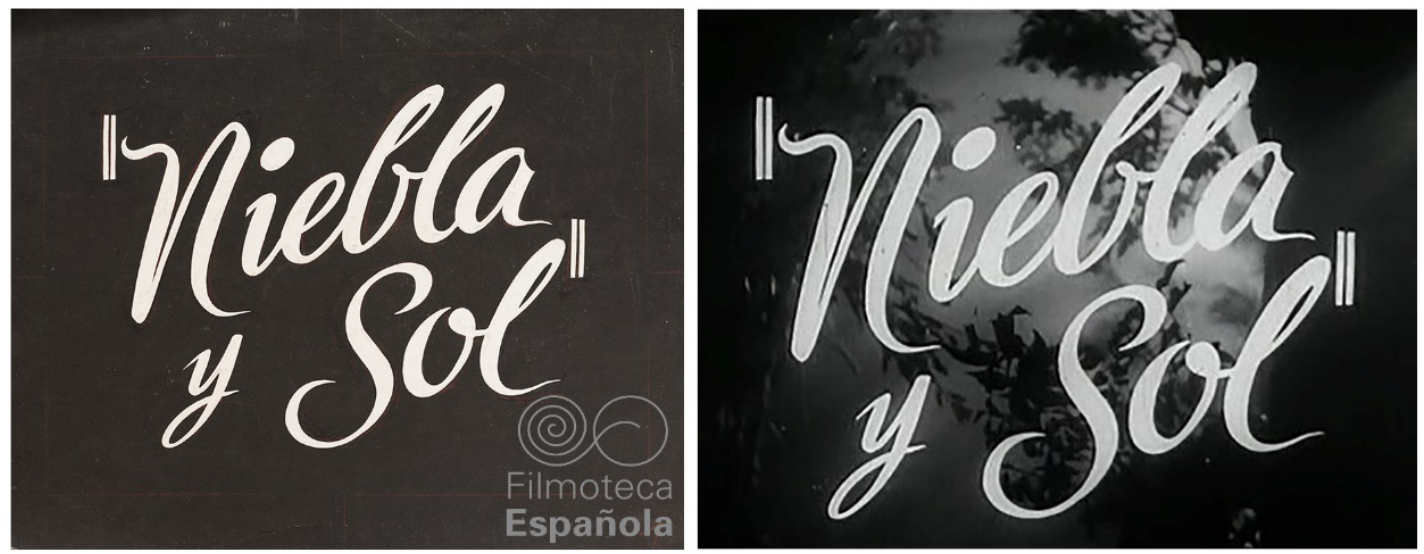

F6. Dibujo de Ramón de Baños y captura del título de la película Niebla y sol (José María Forqué, 1951). Colección-Museo Filmoteca Española.

Queda muchísimo trabajo por hacer para establecer las líneas generales de la evolución del diseño gráfico cinematográfico en nuestro país, pero en estos materiales encontramos ya las primeras pistas y algunos nombres.

\subsection{Los dibujantes de rótulos son pioneros de la traducción audiovisual en España}

El estudio de nuestros rótulos nos ha permitido descubrir que, además de ser pioneros del diseño gráfico cinematográfico español, los dibujantes de títulos fueron también pioneros de la historia de la traducción audiovisual en España.

Esta afirmación se sustenta, especialmente, en los materiales recuperados con el sello de Ramón de Baños, entre los que podemos encontrar títulos de películas, nombres de autoridades e, incluso, insertos de cartas, recetas, notas y letreros que se tradujeron al español y se editaron en la versión española de películas foráneas, durante la fase de doblaje, en sustitución de los originales. Prácticamente todos los títulos que podemos agrupar en esta categoría se estrenaron en España en la década de los cuarenta, época en la que estaba prohibido proyectar obras cinematográficas en un idioma distinto al español.

Vemos un ejemplo en la figura 7 (F7), en la que mostramos el dibujo que Ramón de Baños preparó para el título de la versión española de Ansia de amor (Unfinished Business, Gregory La Cava, 1941). Al analizar estos materiales se observa que Baños eliminaba el texto original de los fotogramas que tenía que traducir, los imprimía y, sobre ellos, insertaba el nuevo rótulo en español. De esta 
manera, el inserto era lo más parecido posible al original. Es fácil comprobarlo porque en algunos rótulos se aprecian con claridad las perforaciones del fotograma original.
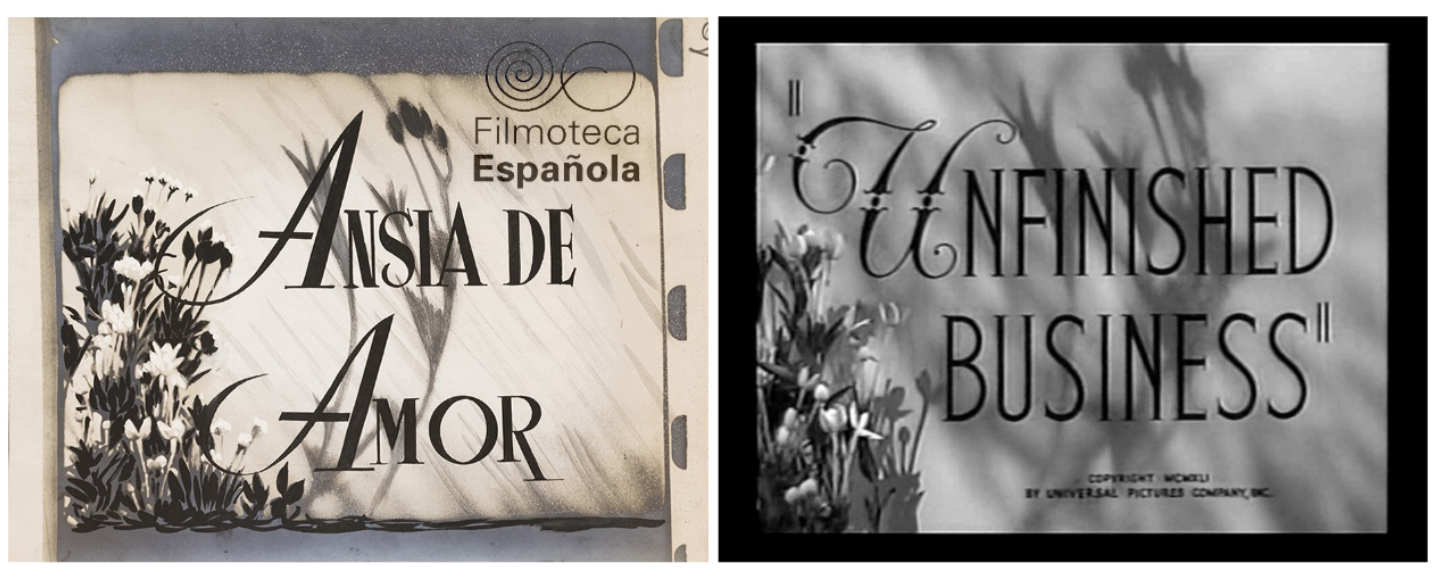

F7. Dibujo de Ramón de Baños para la versión española y captura del título de Ansia de amor (Gregory La Cava, 1941). Colección-Museo Filmoteca Española.

Acceder a las versiones españolas de estas películas es aún más difícil que verificar los títulos producidos en nuestro país. La mayoría de las copias dobladas de estas obras se ha perdido y únicamente se puede acceder a las versiones que las productoras han digitalizado y comercializado a lo largo de las últimas décadas, casi siempre a partir de su montaje original. Hace unos años conseguimos, no obstante, comparar los títulos de crédito traducidos por Ramón de Baños para la película La corona de hierro (La corona di ferro, Alessandro Blasetti, 1941), con una copia en 16mm que se conserva en los Fondos Fílmicos de Filmoteca Española. Para este trabajo Ramón de Baños no sólo tradujo y reinterpretó los títulos de crédito, sino que además reelaboró las 22 páginas del libro miniado que sirve, dentro del relato, para hacer avanzar la acción (Sánchez, 2017). Confiamos en poder comparar otros títulos en el futuro.

Esta parte de la colección incluye títulos de películas italianas, alemanas, francesas, británicas y americanas. Algunos ejemplos son: Rivales (Come and Get It, W.Hawks y H. Wyler, 1936), El jugador de ajedrez (Le joueur d'échecs, Jean Dréville, 1938), Adios, Francis (Auf Wiedersehn, Franziska, Helmut Kautner, 1941), Mi marido está loco (Love Crazy, Jack Conway, 1941), El gran Mitchell (The First of the Few, Leslie Howard, 1941), Bailando nace el amor (You Were Never Lovelier, William A. Seiter, 1942), Treinta segundos sobre Tokio (Thirty Seconds Over Tokyo, Mervyn Leroy, 1944), Pasaje para Marsella (Passage to Marseille, Michael Curtiz, 1944), Los Blandings ya tienen casa (Mr. Blandings 
Builds His Dream House, H.C. Porter, 1948), Crimen en el velódromo (Drame au Vel'd'Hiv, Maurice Cam, 1949) y Nosotras las mujeres (Siamo donne, A. Guarini, R. Rosellini y L. Visconti, 1953).

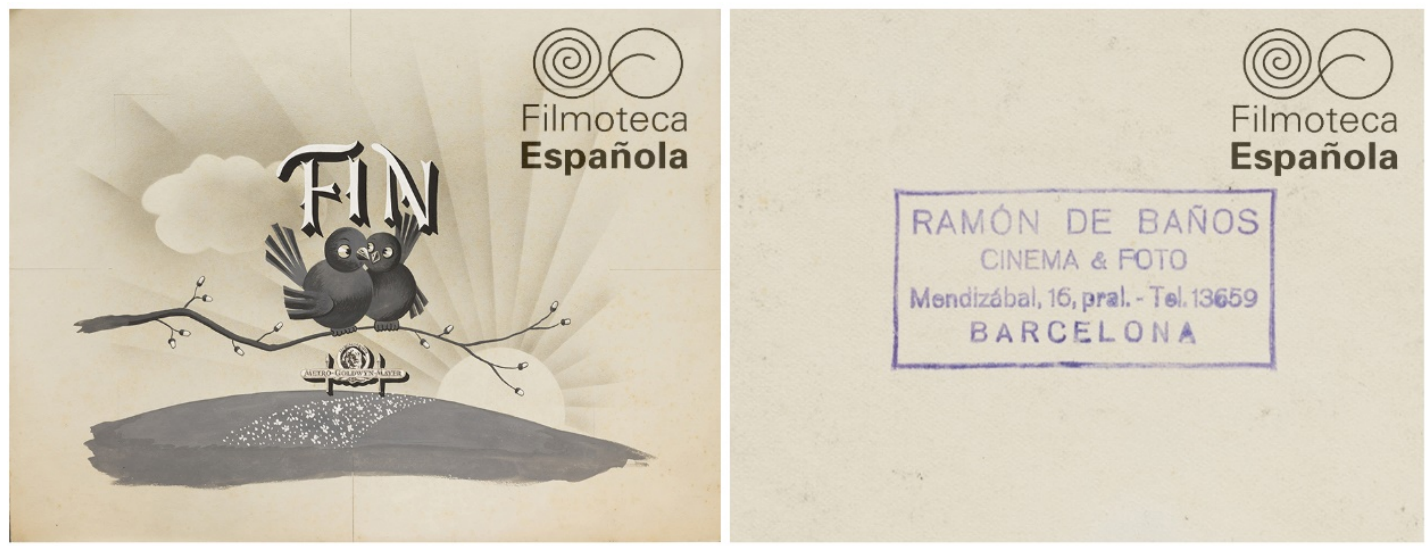

F8. Dibujo de Ramón de Baños para la versión española de Mi marido está loco (Jack Conway, 1941) y sello que aparece al dorso del cartón. Colección-Museo Filmoteca Española.

\section{Conclusiones}

Llegados a este punto, podemos confirmar que esta investigación ha sido capaz de contestar a todas las preguntas que nos hacíamos al abordar el estudio de los materiales que forman parte de esta colección.

Nuestro primer interrogante hacía alusión al número de documentos que teníamos entre manos. La colección, que a simple vista parecía inabarcable, consta en este momento de 1028 documentos. Algunos de ellos son sólo fragmentos y recortes, pero hemos podido comprobar que pertenecen a títulos de películas concretas y eso nos ha permitido identificarlos y darles el lugar que les corresponde dentro de este lote. Muchos de estos rótulos se articulan en torno a 184 títulos de películas. Otros pertenecen a películas publicitarias sin un nombre asignado o están pendientes de que se descubran nuevos documentos que nos permitan comprobar su título. No descartamos que la colección continúe creciendo. De hecho, confiamos en la posibilidad de que en el futuro aparezcan nuevos documentos.

De igual manera, en el futuro esperamos poder cruzar los datos de esta colección con los de otras filmotecas de nuestro territorio. Sabemos que otras instituciones conservan materiales similares e, incluso, complementarios. A partir de ahora 
una de nuestras líneas de trabajo va a ser la de intentar abrir vías de colaboración que nos permitan ampliar el conocimiento que tenemos de estos rótulos.

En segundo lugar, nos preguntábamos de dónde habían venido estos rótulos y en qué momento habían llegado a Filmoteca Española. Hemos podido constatar que casi todas las piezas de la colección llegaron a la institución en los años 70 y 80. En aquel momento no se contaba con los sistemas de registro y entrada de materiales que se utilizan ahora, pero tenemos datos que indican que la mayor parte de la colección procede de los archivos de Ramón de Baños y de Hermic Films, cuyos títulos de crédito corrían a cargo de Manuel Hernández Sanjuán. Esto nos permite, a su vez, atribuir la autoría de muchos de los rótulos a ambos autores y dar respuesta, con ello, a otro de nuestros interrogantes.

En lo que respecta a las preguntas sobre su datación, hemos comprobado que los documentos fueron elaborados durante las décadas de los cuarenta, cincuenta y sesenta. La periodización ha sido posible gracias a la identificación de los títulos de las películas en las que aparecían los rótulos, a su fecha de producción y a su fecha de estreno en España. Además de permitirnos ubicar los rótulos temporalmente, la identificación de los títulos nos ha dejado conocer cuál era la función de cada dibujo y de cada texto. De la localización de las películas hemos podido extraer que una parte de los rótulos se dibujó para las cabeceras originales de películas y documentales españoles y otra parte para la versión doblada de títulos internacionales.

Por último, esta investigación ha dado respuesta a una pregunta personal que nos hacíamos en privado y que no hemos incluido en nuestra introducción: ¿tiene alguna utilidad dedicar tantos años a organizar estos papeles? Afortunadamente, la respuesta ha sido positiva porque, si en su estado original el lote parecía un cúmulo de papeles de poca utilidad, una vez organizados vemos que se trata de una colección de gran interés que permite profundizar en el estudio de la historia de nuestro cine desde múltiples perspectivas. El repaso completo de todos los rótulos que tenemos entre manos plantea múltiples nuevas preguntas cuya respuesta puede, sin duda, enriquecer el conocimiento que tenemos de los títulos de películas y documentales producidos entre las décadas de los 40 y los 60 en nuestro país. 
Más importante aún es el hecho de que, gracias a esta investigación, la colección ha quedado organizada y es consultable a través de las bases de datos internas de Filmoteca Española. No cambian sus condiciones de conservación, que siempre han sido buenas, pero sí aumenta la accesibilidad a los datos que ofrecen estos paratextos fílmicos. Ahora se inicia la etapa de difusión, que sólo puede hacerse a través del estudio y análisis de los materiales.

Confiamos en que este artículo despierte el interés de expertos con capacidad para explotar el potencial que tienen estos documentos desde perspectivas más complejas, analíticas e interpretativas. Ojalá este sea únicamente el primer paso de una larga secuencia de estudios.

\section{Referencias bibliográficas}

Allison, D. (2002). Promises in the Dark. Opening Title Sequences in American Feature Films of the Sound Period. Norwich: University of East Anglia, Phd Thesis.

http://ethos.bl.uk/OrderDetails.do?uin=uk.bl.ethos.247223

Allison, D. (2006). Novelty Title Sequences and Self-Reflexivity in Classical Hollywood Cinema. Screening the Past, 20.

http://tlweb.latrobe.edu.au/humanities/screeningthepast/20/noveltytitle-sequences.html

Allison, D. (2015). Film Title Sequences and Widescreen Aesthetics. Film International, 13 (4), 6-19.

Allison, D. (2011). Beyond Saul Bass. A Century of American Film Title Sequences. Film International, January $30^{\text {th }} \quad 2011$. http://filmint.nu/?p=202

Aran, I.Z. (2011). Investigation of Title Sequences, which is one of the elements that Enhance Film Narrative. En Zhou, Q.Y., 2011 International Conference on Applied Social Science, vol II, 117-121. Changsha, Peoples R. China: Hong Kong University of Science \& Technology

Bass, J. \& Kirkham, P. (2011). Saul Bass. A Life in Film and Design. London, Laurence King Publishing.

Blancas Álvarez, S. (2002). El diseño gráfico y el cine: secuencias de títulos diseñados por Saul Bass 1954-1995. Granada: Universidad de Granada.

Blancas Álvarez, S. (2016). Animando los títulos cinematográficos: de los pioneros a Saul Bass. Con $A$ de Animación, 6, 118-134. https://doi.org/10.4995/caa.2016.4800

Bordwell, D., Staiger, J. \& Thompson, K. (1997). El cine clásico de Hollywood. Barcelona, Paidós. 
Braha, Y. y Byrne, B. (2013). A brief history of title sequences. En Creative Motion Graphic Titling for Film, Video and the Web. London: Focal Press.

Cabero, J.A. (1949). Historia de la Cinematografía Española. Once Jornadas: 1896-1948. Madrid, Gráficas Cinema.

Cardona, R. (1999). Instalación y equipamiento de los primeros laboratorios cinematográficos españoles. Archivos de la Filmoteca. Revista de estudios históricos sobre la imagen, 32, 58-65.

Cerdá, M. (2008). Arqueología industrial. Valencia, Universitat de València.

De Lasa, J.F. (1996). Els Germans Baños: aquell primer cinema català. Barcelona, Generalitat de Catalunya - Departament de Cultura.

Gamonal Arroyo, R. (2005). Títulos de crédito. Píldoras creativas del diseño gráfico en el cine. Icono14. Revista científica de comunicación y tecnologías emergentes, 3 (2), 43-67. https://doi.org/10.7195/ri14.v3i2.418

García Maroto, E. (1988). Aventuras y desventuras del cine español. Barcelona, Plaza y Janés.

González-Monaj, R. (2016). Pablo Núñez. Los créditos de la imaginación. Con $A$ de Animación, 6, 30-41. https://doi.org/10.4995/caa.2016.4787

Horak, J.C. (2014). Saul Bass. Anatomy of Film Design. Lexington, University Press of Kentucky.

Klecker, C. (2015). The other kind of film frames: a research report on paratexts in film. World and Image, 31 (4), 402-413. https://doi.org/10.1080/02666286.2015.1053035

Llorens, A. \& Uris, P. (2001). Miles de metros: a propósito de Pablo Núñez. Huesca: Festival de Cine de Huesca.

López, J. (1960). Cine documental español. Madrid, Ediciones Rialp.

Noordegraaf, J.; Saba, C.G.; Le Maître, B; Hediger V. (eds). (2013). Preserving and Editing Media Art. Challenges and Perspectives. Amsterdam: Amsterdam University Press.

Parikka, Jussi (2012). What is Media Archaeology. Malden: Polity Press.

Ramírez Barredo, B. (2016). Los títulos de crédito. Marca de las películas. Madrid: UCM. https://eprints.ucm.es/41930/1/T38581.pdf

Rey, E. (2013). Los títulos de crédito como marco. Un análisis dentro del llamado cine histórico. III Congreso Internacional de Historia y Cine: modelos de interpretación para el cine histórico. Santiago de Compostela: Universidad de Santiago de Compostela.

Rey, E. (2016). Los títulos de crédito como marco de la obra fílmica. 1958-1969. Tesis Doctoral. Barcelona: Universitat Pompeu Fabra. https://www.tdx.cat/handle/10803/350566

Sánchez, M.B. (2017). Ramón de Baños y la versión española de los títulos de crédito de "La corona de hierro" (1941), de Alessandro Blasetti. V Congreso Internacional de Historia y Cine: escenarios del cine histórico. Madrid, Universidad Carlos III. https://e-archivo.uc3m.es/handle/10016/24818 
Solana, G. \& Boneu, A. (2007). Uncredited. Diseño gráfico y títulos de crédito. Barcelona, Index Books.

Solana, G. \& Boneu, A. (2016). Secuencias de títulos de animación en series de ficción. Un paisaje general. Con $A$ de Animación, 6, 96-102. https://doi.org/10.4995/caa.2016.4798

Stanizek, G. (2009). Reading the Title Sequence. Cinema Journal, 48, $\mathrm{n}^{0} 4$, pp.44-58. https://muse.jhu.edu/article/317402

Truffaut, F. (2010). El cine según Hitchcock. Madrid, Alianza Editorial.

Tylski, A. (2008). Le générique de cinéma. Histoire et fonctions d'un fragment hybride. Toulouse, Presses Universitaires du Mirail.

Zons, A. (2015) Projecting the Title. World and Image, 31 (4), 442-449. https://doi.org/10.1080/02666286.2015.1053038 